Paper ID \#18220

\title{
The Forgotten Steps of Engineering Design: Design-Build Experiences and their Downstream Effect on Capstone Design Projects
}

\author{
Dr. William H. Guilford, University of Virginia
}

Will Guilford is an Associate Professor of Biomedical Engineering at the University of Virginia. He is also the Undergraduate Program Director for Biomedical Engineering, and the Director of Educational Innovation in the School of Engineering. He received his B.S. in Biology and Chemistry from St. Francis College in Ft. Wayne, Indiana and his Ph.D. in Physiology from the University of Arizona. Will did his postdoctoral training in Molecular Biophysics at the University of Vermont under David Warshaw. His research interests include novel assessments of educational efficacy, the molecular basis of cell movement, and the mitigation of infectious diseases.

\section{Dr. Timothy E. Allen, University of Virginia}

Dr. Timothy E. Allen is an Associate Professor in the Department of Biomedical Engineering at the University of Virginia. He received a B.S.E. in Biomedical Engineering at Duke University and M.S. and Ph.D. degrees in Bioengineering at the University of California, San Diego. Dr. Allen's teaching activities include coordinating the undergraduate teaching labs and the Capstone Design sequence in the BME department at the University of Virginia, and his research interests are in the fields of computational biology and bioinformatics. He is also interested in evaluating the pedagogical approaches optimal for teaching lab concepts and skills, computational modeling approaches, and professionalism within design classes.

\section{Dr. Shayn M. Peirce, University of Virginia}

I am Professor of Biomedical Engineering at the University of Virginia. I have joint appointments in the Department of Plastic Surgery and the Department of Ophthalmology. I have deep interest in studying the structural and functional adaptations of tissues, particularly the microvasculature, in both health and disease. My lab develops strategies to manipulate tissue growth and remodeling for the purposes of limiting tissue degeneration and enhancing tissue regeneration and wound healing. We combine agent-based computational modeling, in vivo imaging, and new experimental approaches to examine and control the multi-cell interactions involved in microvascular network patterning. We are particularly interested in learning how diseases, such as diabetes and cardiovascular disease, affect angiogenesis and arteriogenesis in different tissues, such as skin, retina, and muscle. My research spans basic science discovery to the design of therapies for regenerative medicine. Current projects seek to exploit perivascular cells (pericytes), inflammatory cells (e.g. monocytes and macrophages), and tissue-resident stem cells to invoke tissue regeneration during acute and chronic inflammation. I collaborate extensively with clinician scientists and medical doctors, as well as other engineers, both at UVA and at other institutions. I teach graduate level and undergraduate level courses on cell and molecular physiology and computational systems biology. I am fellow in the American Institute for Medical and Biological Engineering (AIMBE), and past recipient of the MIT Technology Review TR100 Young Innovator Award and the Biomedical Engineering Society's Rita Schaffer Award. 


\section{The forgotten steps of engineering design: design-build experiences and their downstream effect on capstone design projects}

Various stages are ascribed to the engineering design process, but they typically include (1) problem identification, (2) research and conceptualization, (3) prototyping, (4) testing, and finally (5) iteration of some or all of steps 1-4. Design courses are often tasked with teaching all of these in the span of a single semester. The coverage is often biased; problem identification, research, and brainstorming are easily taught in a traditional classroom. Fabrication, testing, and iteration, in contrast, are often emphasized less. This is presumably due to the facilities, time, and material costs needed to execute these steps.

We posit that immersive design-build-iterate experiences are a vital part of early-year undergraduate engineering education, and that they can improve student outcomes in their major design experiences. This hypothesis is supported by the "spacing effect" - the accepted effect of improved learning by exposing students repeatedly to concepts but over a sufficiently long span of time [1]. The spacing effect is believed to hold not only of cognitive skills, but of motor skills also [2]. Further, it has been suggested that students need to be confronted with "the differences between their instinctive design behaviors and the behaviors of effective engineering designers" [5] in order to learn, and therefore apply, these skills. It is natural to assume that iterative, immersive projects would accomplish these goals.

To test the hypothesis that early exposure to immersive design-build-iterate experiences improve student outcomes in their major design experience, we compared two years of fourth year capstone design outcomes in a biomedical engineering program. Students in this program take a required second-year course in biomedical design. In the control year of this study, the secondyear students engaged in traditional design instruction that emphasized steps 1 and 2. Students themselves identified fabrication resources, and only one prototype was required. In the intervention year, students were instead engaged in design instruction that emphasized steps 3 through 5. Of particular note, these students were engaged for half the semester in hands-on fabrication of devices, and were required to prototype their design solutions twice to emphasize the importance of iteration.

We found that an immersive design-build-iterate experience in the $2^{\text {nd }}$ year is associated with narrowly focused improvements in $4^{\text {th }}$ year capstone design outcomes. Specifically, the built quality of the final prototype was improved in projects that focused on mechanical design, but these improvements did not extend to other types of projects or to other late steps in the engineering design process. We discuss our findings in terms of the spacing effect, and other means by which engineering design behavior might be reinforced.

\section{Control year}

The control year of this design course was based around (a) a semester-long project that culminated in an alpha prototype, and (b) a series of 1 to 3-week lecture learning modules meant to deliver a broad overview of fundamentals pertaining to biomedical engineering (Table 1). The design problem - issues commonly encountered in a neonatal intensive care unit - was introduced in week 3 by a clinician, and the design project extended throughout the semester. Design-related assignments were due at regular intervals. 


\begin{tabular}{|l|l|l|}
\hline \multicolumn{3}{|l|}{ Table 1: Control year weekly in-class subjects and design project milestones / activities } \\
\hline Week & Classroom subjects & Design activities and milestones \\
\hline 1 & Engineering basics & \\
\hline 2 & Engineering basics & \\
\hline 3 & Engineering basics & $\begin{array}{l}\text { Problem introduced } \\
\text { Problem statement, user needs, design specifications }\end{array}$ \\
\hline 4 & Bioelectricity and circuits & Summary of prior art \\
\hline 5 & Bioelectricity and circuits & Summary of brainstormed solutions \\
\hline 7 & Computation & \\
\hline & Computation & \\
\hline 8 & Design and CAD & Finalized conceptual solution \\
\hline 9 & Biochemical principles & CAD drawing of a single component of the design \\
\hline 10 & Biochemical principles & \\
\hline 11 & Biomaterials & \\
\hline 12 & Biomaterials & Memo: prototype final design, and FDA path \\
\hline 13 & Design integration & Testing and validation data from prototype \\
\hline 14 & Design integration & Draft PowerPoint slides for product pitch \\
\hline Finals & & Prototype due, along with an executive summary \\
\hline
\end{tabular}

Note that aside from one week of CAD training, there was relatively little hands-on training in two of the latter stages of the engineering design process - that is, prototyping, testing. In fact, students in the control year sought out facilities and materials on their own, generally did not have access to a machine shop, and were not required to spend any particular amount of time on the prototyping or testing steps. Further, no iteration of the design process was expected or required. These features are anecdotally typical of undergraduate design courses.

\section{Intervention year}

The subsequent year, the class was taught in an immersive, project-based manner. Rather than modules that provided students a broad overview of topics in biomedical engineering, all activities were directly geared toward completion of the project (Table 2).

As in the control year, students were presented by a clinician with a real, unsolved set of clinical problems - in this instance, problems in the cleaning and disinfection of clinical instruments. Students then worked in teams to solve the problem. Teams were required to progress through all of the stages of the engineering design process, including iteration. To this end, for the first fiveweeks of the semester, teams were lead through formal exercises in problem identification, research, and iterative brainstorming. They were also formally trained for two weeks in CAD (as compared to one week in the Control), and in the fundamentals of using microcontrollers.

Teams transitioned mid-semester to hands-on design-build experiences lasting six weeks. During those six weeks, class met in the regular classroom only twice. Instead, student teams were required to sign up for a minimum of 3 hours of "shop flex time" - that is, student teams signed up for blocks of time when members were available, and when the machine shops were open. While the minimum number of hours any team could select was 3 , teams were permitted to 
request up to 8 hours per week by the end of the semester. The instructor was available in the machine shops for those same 20-25 hours per week to monitor student work, to ensure safety, and to provide assistance and tool training.

Before students could begin work in the shop, they were required to watch one hour of training videos on shop safety, and best practices for using the most common tools. They then had to pass a quiz on these best practices with a score of $70 \%$ or better before being admitted to the shops. If they failed to do so, they were required to return on a different day to re-take the quiz. The failure rate on the quiz was approximately $6 \%$.

Teams were required to create both first- and second-generation prototypes of a functioning device. In fact, teams were suggested to create two first-generation prototypes - one for each of their top two conceptual designs. The first-generation prototypes were required to demonstrate the primary function of the device; they could omit any secondary functions or features. These were tested, and presented before the rest of the class to garner feedback. The teams then had three more weeks of shop time to produce a new, second-generation prototype. The general requirements for the second-generation were that it be fully functional (including secondary functions and features), and be well-made.

As a result of this format, equal emphasis was placed on the latter stages of the engineering design process (i.e. prototyping, testing, and iteration) as on the early stages. In fact, $50 \%$ of the course grade was determined by the two physical builds, and a final invention disclosure.

\begin{tabular}{|l|l|l|}
\hline \multicolumn{2}{|l|}{ Table 2: Intervention year weekly in-class subjects and design project milestones / activities } \\
\hline Week & Classroom subjects & Design activities and milestones \\
\hline 1 & Introduction to the problem & Non-disclosure agreement \\
\hline 2 & $\begin{array}{l}\text { Q\&A with clinician } \\
\text { Ideation and sketching }\end{array}$ & $\begin{array}{l}\leftarrow \text { same as } \\
\leftarrow \text { same as }\end{array}$ \\
\hline 3 & Brainstorming and IP & $\begin{array}{l}\text { Pitches } \\
\text { Permanent design teams formed }\end{array}$ \\
\hline 4 & $\begin{array}{l}\text { Measuring and drawing of parts } \\
\text { Brainstorming on materials }\end{array}$ & $\leftarrow$ same as \\
\hline 5 & Brainstorming on fabrication & $\leftarrow$ same as \\
\hline 6 & CAD & \\
\hline 7 & CAD & Shop training \\
\hline 8 & Materials, machining, and assembly & Shop \\
\hline 9 & CAD assignment due & Shop \\
\hline 10 & & Shop \\
\hline 11 & & First-generation prototypes due \\
\hline & First-generation prototype presentations & Shop \\
\hline 12 & Microcontrollers & Shop \\
\hline 13 & & $\begin{array}{l}\text { Shop } \\
\text { Second-generation prototypes due }\end{array}$ \\
\hline 14 & & \\
\hline Finals & Final presentations & \\
\hline & & \\
\hline
\end{tabular}


It is worth reemphasizing that time spent prototyping was treated as "in-class time" with direct access to the instructor. This is in contrast to the control year, during which prototyping and testing were conducted as homework. However, while the intervention year was an immersive experience, students and teams still learned fabrication skills on an as-needed basis (with the exception of CAD and microcontrollers).

\section{Metrics and statistics}

We analyzed the $4^{\text {th }}$ year capstone design projects, completed two-years later, of students who took each of these variations on the $2^{\text {nd }}$ year design course. Capstone projects from these two years were sorted into categories, and only considered projects that focused on product design (as opposed to computational, therapeutic, process, and other forms of design). Our rationale was that any downstream impacts would most likely affect projects that utilized similar skills as those emphasized in the $2^{\text {nd }}$ year course. The projects of 14 teams from each year fell into this category. We further categorized product design projects as being primarily electrical or mechanical in nature. Four specific examples of product design projects were:

1. (Mechanical) Students designed a physical model as a simulation tool for training otolaryngology residents to properly use an esophagoscope.

2. (Mechanical) Students tested and optimized a lightweight, compact, and robust knee brace hinge mechanism for patients with osteoarthritis.

3. (Electrical) A team developed a personalized, remote telemonitoring system for patients diagnosed with congestive heart failure that measured chest bioimpedance at home.

4. (Electrical) A team developed a wearable sock with embedded flex sensors as a means for preliminary home diagnosis of suspected ankle sprains.

Teams and their projects were scored on four metrics of engineering design behavior.

1. Build difficulty

2. Early generation of first prototype

3. Iteration of the design process

4. Quality of the final prototype

The capstone instructor ranked build quality on an absolute scale of 1-5. The other three metrics were scored both on an absolute and on a rank-ordered basis. To help eliminate subjectivity from the former, the instructor aggregated teams/projects from the two years, and placed them in order from earliest generation of a prototype (1) to latest (28). The years were disaggregated, and the rankings between the two years compared by the non-parametric Mann Whitney U test. This process was repeated for the iteration and quality metrics. Absolute scores, in contrast, were compared by unpaired t-test.

\section{Results and discussion}

The structure and design/build activities of the capstone teams were similar in most respects, regardless of which version of the $2^{\text {nd }}$ year course was taken. The teams were of similar size $(2.5$ and 2.7 students/team, $2^{\text {nd }}$ year control vs intervention, respectively). Similar numbers of teams used CAD as an integral part of their design process (11 vs. 10), and similar numbers of teams 
used microcontrollers in their projects (5 vs. 6). Further, the difficulty of the prototype build they undertook did not differ significantly between the two years $(p=0.08)$.

There was a trend toward improved scores in iteration and quality for capstone teams having been exposed to the $2^{\text {nd }}$ year intervention, but the differences were not significant (Table 3 ). Likewise, there were across-the-board trends toward improved relative rankings of capstone teams having been exposed to the intervention, but these too failed to rise to the level of significance. Note that these statistics included scores and rankings from all product design projects.

\begin{tabular}{|c|c|c|c|c|}
\hline & & $\begin{array}{c}\text { Early } \\
\text { prototype }\end{array}$ & $\begin{array}{l}\text { Iteration } \\
\text { of design }\end{array}$ & $\begin{array}{l}\text { Quality of } \\
\text { final prototype }\end{array}$ \\
\hline \multirow{3}{*}{ 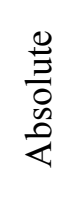 } & Control mean score & $2.71 / 5$ & $2.97 / 5$ & $5.57 / 10$ \\
\hline & Intervention mean score & 2.71 & 3.07 & 6.50 \\
\hline & $\mathrm{p}$ & 0.500 & 0.375 & 0.120 \\
\hline \multirow{4}{*}{ 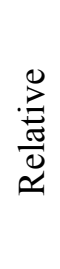 } & Control mean rank & 15.6 & 15.4 & 16.4 \\
\hline & Intervention mean rank & 13.4 & 13.6 & 12.6 \\
\hline & $\mathrm{U}$ & 83 & 86 & 71 \\
\hline & $\mathrm{p}$ & 0.251 & 0.298 & 0.111 \\
\hline
\end{tabular}

If we instead consider those projects best aligned to the intervention experiences, - that is, capstone projects that emphasized mechanical design - then we find that the quality of the final prototype in capstone was significantly improved for students from the $2^{\text {nd }}$ year intervention relative to the control group (Table 4). Significance held whether we compared absolute scores or relative ranks. Iteration scores approached significance.

An accepted tenet in education is that exposing students repeatedly to concepts but over a sufficiently long span of time leads to improved learning. This is called the "spacing effect" [1]. This is thought to be true not only of cognitive skills, but of motor skills [2]. It is surprising, then, that having been immersed in the full breadth of the engineering design process at least twice over a two-year period did not result in greater gains in the latter stages of the engineering design process. Admittedly, our sample size was small (14 student teams each from the control and intervention years).

It is telling, however, that significant changes were found only in the quality of the final capstone prototype build, and then only for those projects that were primarily mechanical in nature. This suggests that the impacts of our $2^{\text {nd }}$ year intervention were extremely narrow, restricted to the manual skills that were so heavily emphasized in the latter half of the $2^{\text {nd }}$ year course. 
It is also possible that more or different sorts of exposures to the engineering design process are needed to achieve improvements in student design abilities. Indeed, we have shown previously that a single immersive design-build experience fails to yield appreciable gains in engineering design process knowledge [3] - a metric that has been shown to correlate well with what engineering students will actually do when confronted with an engineering problem [4].

\begin{tabular}{|c|c|c|c|c|}
\hline & & $\begin{array}{l}\text { Early } \\
\text { prototype }\end{array}$ & $\begin{array}{l}\text { Iteration } \\
\text { of design }\end{array}$ & $\begin{array}{c}\text { Quality of } \\
\text { final prototype }\end{array}$ \\
\hline \multirow{3}{*}{\begin{tabular}{l}
$\stackrel{0}{\Xi}$ \\
0 \\
0 \\
\multirow{2}{Z}{}
\end{tabular}} & Control mean score & $2.45 / 5$ & $2.64 / 5$ & $4.91 / 10$ \\
\hline & Intervention mean score & 2.64 & 3.27 & 6.55 \\
\hline & $\mathrm{p}$ & 0.364 & 0.097 & $0.034 *$ \\
\hline \multirow{4}{*}{ 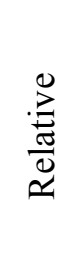 } & Control mean rank & 17.1 & 17.6 & 19.2 \\
\hline & Intervention mean rank & 14.6 & 11.9 & 12.3 \\
\hline & $\mathrm{U}$ & 49 & 39 & 31 \\
\hline & $\mathrm{p}$ & 0.236 & 0.084 & $0.029 *$ \\
\hline
\end{tabular}

Our work suggests that a single immersive design-build-iterate experience does not, on its own, lead to broad improvements in engineering design behaviors, even if those experiences are repeated over time. They may, however, result in improvements in specific design behaviors. We may need to consider fundamental changes to how we teach the engineering design process if we seek improve the design skills of the students we graduate.

\section{Literature cited}

[1] N. J. Cepeda, H. Pashler, E. Vul, J. T. Wixted, and D. Rohrer, "Distributed practice in verbal recall tasks: A review and quantitative synthesis," Psychol. Bull., vol. 132, no. 3, pp. 354-380, 2006.

[2] C. H. Shea, Q. Lai, C. Black, and J.-H. Park, "Spacing practice sessions across days benefits the learning of motor skills," Hum. Mov. Sci., vol. 19, no. 5, pp. 737-760, Nov. 2000.

[3] W. H. Guilford, A. S. Blazier, and A. Becker, "Work in Progress: The Effect of Immersive Design-Build Experiences on Knowledge of the Engineering Design Process: American Society for Engineering Education," presented at the 2016 ASEE Annual Conference \& Exposition, 2016.

[4] R. Bailey, “Don't Tell Me What You Know, Tell Me What You Would Actually Do! Comparing Two Design Learning Assessment Approaches," presented at the 2016 ASEE Annual Conference \& Exposition, 2016.

[5] R. Bailey, "The Challenge of Developing Transferable Problem Formulation Design Behaviors in First-year Students," 2015, p. 26.1510.1-26.1510.10. 